\title{
Pylorus preserving loop duodeno-enterostomy with sleeve gastrectomy - preliminary results
}

\author{
Jodok Matthias Grueneberger ${ }^{1 *}$, Iwona Karcz-Socha ${ }^{2}$, Goran Marjanovic ${ }^{1}$, Simon Kuesters ${ }^{1}$, \\ Krystyna Zwirska-Korczala², Katharina Schmidt ${ }^{3}$ and W Konrad Karcz ${ }^{3}$
}

\begin{abstract}
Background: Bariatric operations mostly combine a restrictive gastric component with a rerouting of the intestinal passage. The pylorus can thereby be alternatively preserved or excluded. With the aim of performing a "pylorus-preserving gastric bypass", we present early results of a proximal postpyloric loop duodeno-jejunostomy associated with a sleeve gastrectomy (LSG) compared to results of a parallel, but distal LSG with a loop duodeno-ileostomy as a two-step procedure.
\end{abstract}

Methods: 16 patients underwent either a two-step LSG with a distal loop duodeno-ileostomy (DIOS) as revisional bariatric surgery or a combined single step operation with a proximal duodeno-jejunostomy (DJOS). Total small intestinal length was determined to account for inter-individual differences.

Results: Mean operative time for the second-step of the DIOS operation was $121 \mathrm{~min}$ and $147 \mathrm{~min}$ for the combined DJOS operation. The overall intestinal length was $750.8 \mathrm{~cm}$ (range 600-900 cm) with a bypassed limb length of $235.7 \mathrm{~cm}$ in DJOS patients. The mean length of the common channel in DIOS patients measured 245.6 $\mathrm{cm}$. Overall excess weight loss (\%EWL) of the two-step DIOS procedure came to $38.31 \%$ and $49.60 \%$, DJOS patients experienced an \%EWL of $19.75 \%$ and $46.53 \%$ at 1 and 6 months, resp. No complication related to the duodeno-enterostomy occurred.

Conclusions: Loop duodeno-enterosomies with sleeve gastrectomy can be safely performed and may open new alternatives in bariatric surgery with the possibility for inter-individual adaptation.

\section{Background}

Bariatric surgery has proven to be the most effective treatment for long-term weight loss and metabolic rebalancing in obese patients [1,2]. Most procedures combine a restrictive gastric component with a rerouting of the intestinal passage. Prominent examples are the Roux-en-Y gastric bypass (RYGB) or the biliopancreatic diversion (BPD). Gastric restriction either involves the entire stomach therefore preserving the pylorus when reconstructing the intestinal passage, or only the proximal part of the stomach is used to form a gastric pouch thus leaving a remnant stomach. Passage reconstruction then requires a gastro-enterostomy.

\footnotetext{
* Correspondence: jodok.grueneberger@uniklinik-freiburg.de 'Department of General and Visceral Surgery, University of Freiburg, Hugstetter Strasse 55, 79106 Freiburg, Germany

Full list of author information is available at the end of the article
}

Preserving the pylorus when bypassing the duodenum has led to important technical changes in bariatric surgery. In order to avoid a dumping syndrome and marginal ulcers that occasionally occurred after Scopinaro's initial BPD, Marceau et al. successfully changed the technique to perform a biliopancreatic diversion with duodenal switch (BPD/DS) with similar limb variations, using however a postpyloric reconstruction [3].

The RYGB generally is one of the best established procedures in bariatric surgery [4]. However the failure rate with weight regain due to a dilatation of the gastric pouch, gastro-jejunostomy and proximal jejunum is up to $35 \%$ [5]. Recently, bile reflux was identified as one important cause of postoperative pain [6]. Again, a postpyloric reconstruction seems tempting for this procedure.

We here present perioperative data of a proximal (similar to RYGB) and distal (similar to BPD/DS) postpyloric loop duodeno-enterostomy with sleeve gastrectomy. The distal duodeno-enterostomy, based on the 
earlier described single anastomosis duodeno-ileostomy associated to a sleeve gastectomy (SADI-S) operation [7], was performed as revisionary bariatric operation.

\section{Methods \\ Patients}

From October 2011 to September 2012, 16 patients underwent loop duodeno-enterostomies for bariatric surgery. Explicit written informed consent for operation and data recording was obtained from all patients. Data recording and evaluation was approved by the ethics committee of the University of Freiburg (ref. number 321/13) and was in accordance with the Declaration of Helsinki. A proximal duodeno-jejunostomy with sleeve gastrectomy (DJOS) was conducted as an alternative to RYGB in 7 selected patients eligible for bariatric surgery with a body mass index (BMI) range from 35.7 to 47.9 $\mathrm{kg} / \mathrm{m}^{2}$ (median BMI $42.7 \mathrm{~kg} / \mathrm{m}^{2}$ ). In case of previous gastric banding and relevant perigastric scar tissue, instead of a sleeve gastrectomy, a gastric plicature was performed $(n=3 / 7)$ to minimize operative risk. Twostep DIOS was performed as revisionary surgery after failed RYGB due to dumping syndrome $(n=2 / 9)$ or after sleeve gastrectomy with insufficient weight loss alone (3/9) or in combination with persisting type 2 diabetes (T2DM, 4/9). All operations were performed by the same senior surgeon. In order to prevent vitamin deficiencies, besides a multivitamin, patients are prescribed Calcium (500 mg twice daily), Vitamin D3 (1000 IU daily), folic acid (5 mg daily) and iron (100 mg daily) supplementation.

Data recording included length of hospital stay, preoperative BMI, presence of medical comorbidities, intra- and postoperative complications, management of complications, total operative time, common channel length and weight loss. Total intestinal length was recorded only after February 2012. All data were entered prospectively into a custom-designed database. The patients had the same follow-up protocol at the outpatient clinic at $1,3,6$, and 12 months after surgery, followed by an annual visit.

\section{Operative technique}

The patient is placed in the split-leg position with the operating surgeon standing between the legs. Trocar positions are similar to those used for banded sleeve gastrectomy [8].

Sleeve gastrectomy is conducted as described earlier [8]. In case of a stomach plication, we use a modified technique described by Talebpour et al. applying at least two rows of plication using a 3-0 V-Loc ${ }^{\text {tm }}$ Suture (Covidien, Dublin, Ireland) [9]. The second part of the operation (second step, when performing a two-step procedure) begins with separation of the duodenum with an endostapling device (GIA- Roticulators, Covidien, Dublin, Ireland, violet cartridge) under preservation of the right gastric artery. Before performing the duodeno-enterostomy, the length of the small bowel is determined to account for inter-individual differences. After measurement, the omega loop should be placed near the postpyloric duodenum with special attention to intestinal alignment to avoid mesenteric malrotation. The position of the duodeno-enterostomy is determined to be aboral to the Treitz ligament, $1 / 3$ of total small bowel length for DJOS (Figure 1), and $2 / 3$ for DIOS (Figure 2). The duodeno-enterostomy is performed as an antecolic, continuous end-to-side handsewn anastomosis using 3-0 V-loc ${ }^{\mathrm{Tw}}$ sutures (Covidien, Dublin, Ireland, Figure 3). Diluted half-strength methylene blue dye (150-200 ml) is used for leak testing. Finally, a drain is put towards the duodenal stump. In case of a two-step procedure, the second part of the operation is conducted separately, then sparing the top left $5 \mathrm{~mm}$ trocar needed for sleeve gastrectomy.

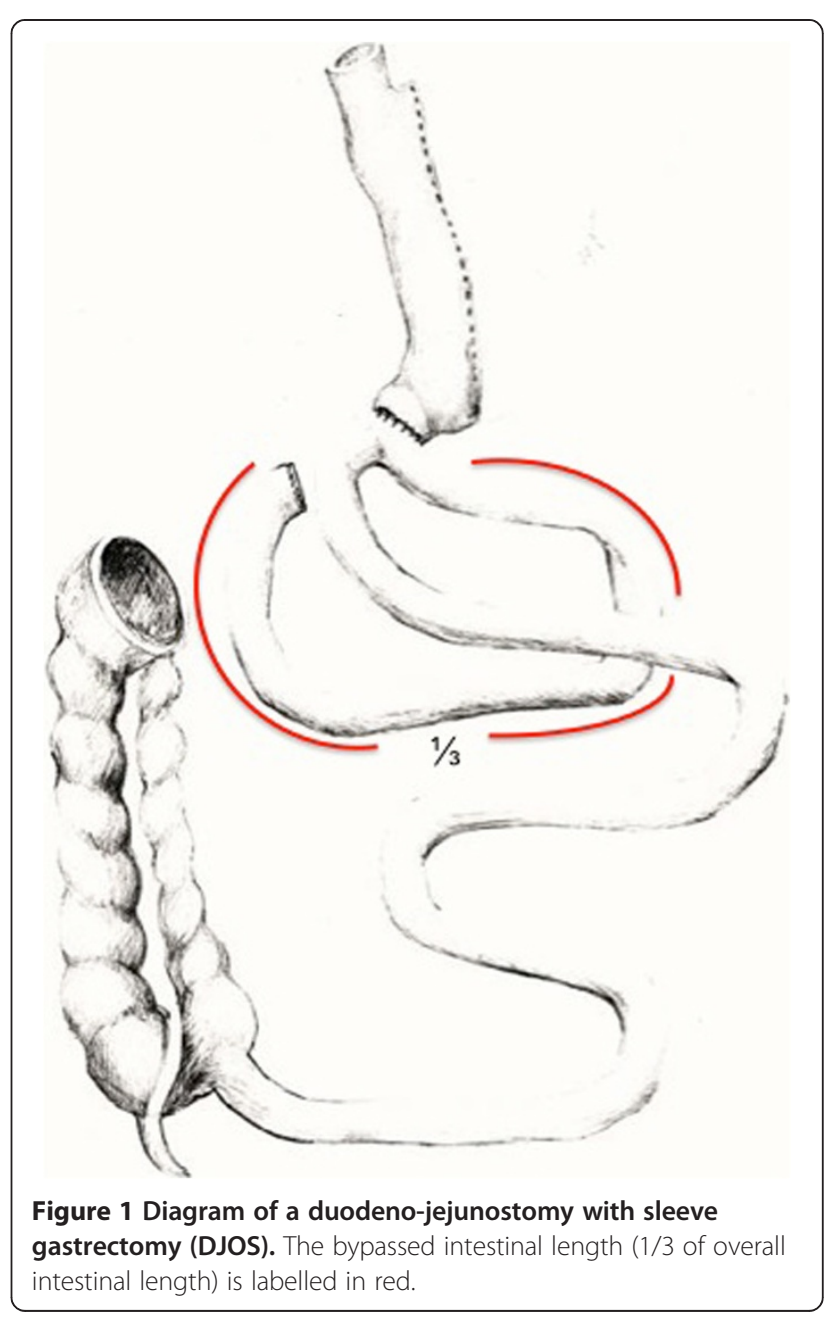




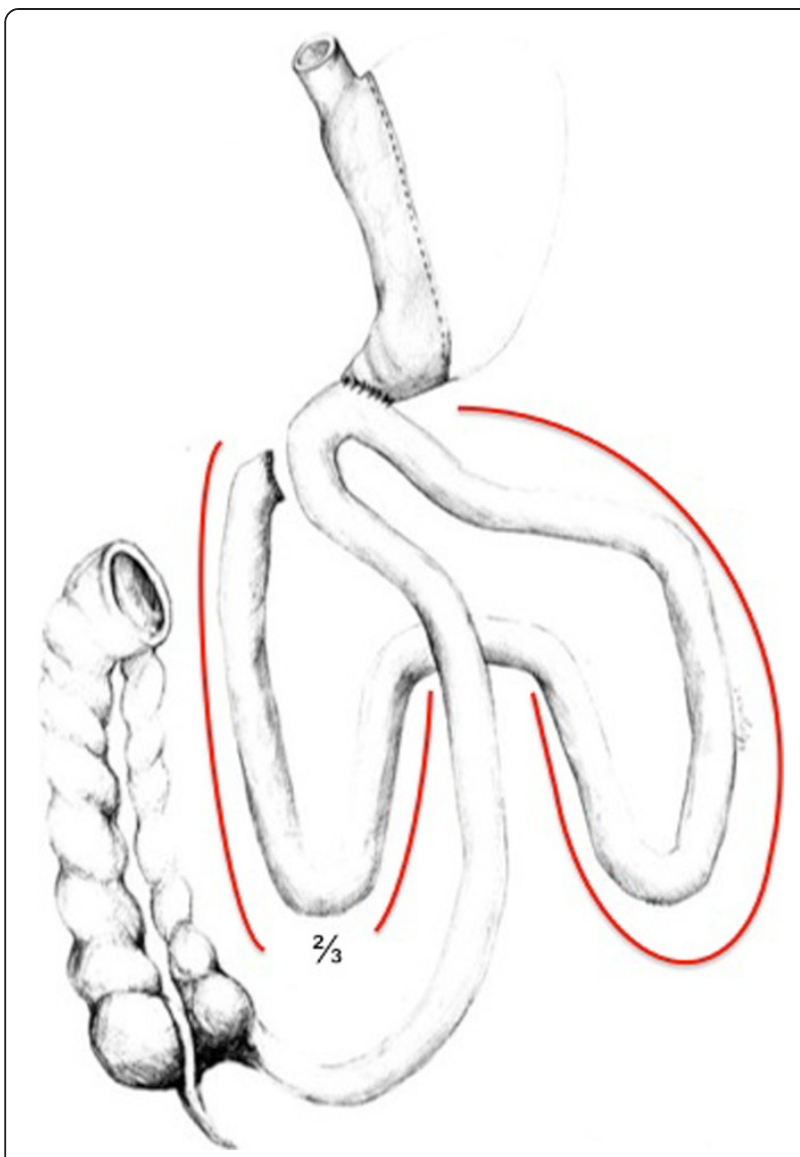

Figure 2 Diagram of a duodeno-ileostomy with sleeve gastrectomy (DIOS). The bypassed intestinal length ( $2 / 3$ of overall intestinal length) is labelled in red.

\section{Statistical analysis}

Prism 5 for Mac OS X (GraphPad Software, Inc.) was used for all statistical analyses. Statistical significance was set at an alpha of 0.05 for all analyses.

\section{Results}

16 patients underwent laparoscopic DIOS and DJOS operations with a mean duration of $121 \mathrm{~min}$ and $147 \mathrm{~min}$, respectively. Overall, 9 patients had undergone previous weight loss surgery, mainly gastric banding (Table 1). A complex gastric reconstruction from RYGB to a sleeve stomach due to uncontrolled dumping syndrome had been conducted earlier in 2 patients. The mean latency between the sleeve and the second step DIOS operation was 17.9 months (Table 1 ).

One intestinal perforation occurred upon insertion of the first trocar in a patient with previous gastric banding and subsequent adhesions to the abdominal wall. No complications specific to the duodeno-enterostomy were noted (Table 2).

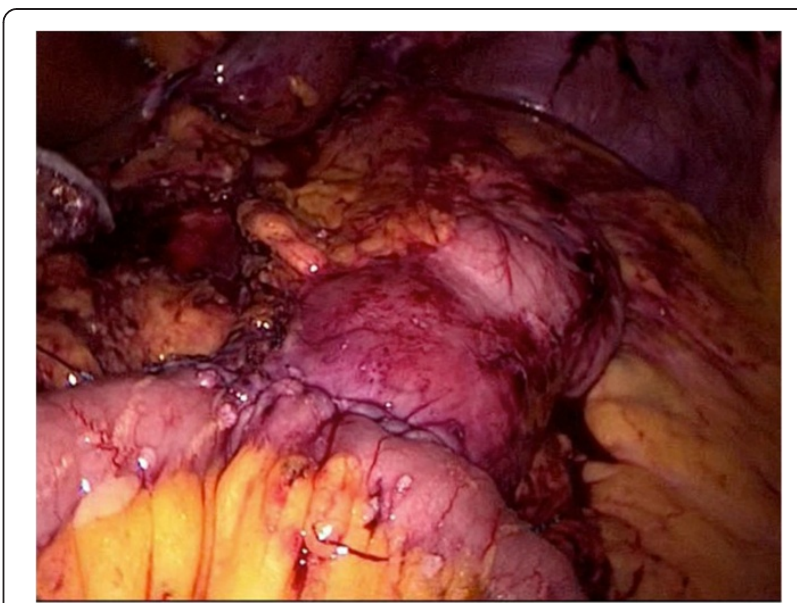

Figure 3 Final aspect of the duodeno-enterostomy.

\section{Intestinal length}

The overall total intestinal length was $750.8 \mathrm{~cm}$ (Table 2). Although there was no correlation of total intestinal length and preoperative bodyweight (linear regression $\mathrm{p}=0.76$ ), the total small intestinal length in DIOS patients was significantly longer than in DJOS patients (Mann-Whitney $\mathrm{P}=0.038$, Table 2).

\section{Weight loss}

The mean preoperative BMI was $40.63 \mathrm{~kg} / \mathrm{m}^{2}$ in DIOS and $41.60 \mathrm{~kg} / \mathrm{m}^{2}$ in DJOS patients (Table 1). Patients after primary DJOS operation presented with an excess weight loss (\%EWL) of $19.75 \%$ and $46.53 \%$ at 1 and 6 months (Figure 4A). The overall \%EWL of the combined DIOS procedure was $38.31 \%$ and $49.60 \%$ (Figure $4 \mathrm{~B}$ ). Mean weight loss through LSG alone was $31.73 \%$ (range -2.67 69.54). Further \%EWL came to $18.73 \%$ at 1 and $33.03 \%$ at 6 months following the second step operation. In this early follow-up, 1 patient did not lose any additional weight after the second step operation despite bypassing $520 \mathrm{~cm}$ of small intestine and clinical signs of malabsorption. Furthermore, control CT sleeve volumetry revealed a small volume of $142 \mathrm{ml}$ at 10 months postoperatively indicating sustained restriction.

\section{Comorbidities}

Prior to LSG, 88.9\% of patients suffered from T2DM. At the time of the second-step DIOS operation, $44.4 \%$ had remained on anti-diabetic medication, $33.3 \%$ on insulin therapy (Table 3). 3 months after completion of the second step, only $11.1 \%$ (1 patient) still needed anti-diabetic medication. Glycated haemoglobin levels dropped from $6.8 \%$ to $5.7 \%$ in DIOS and from $8.0 \%$ to $6.9 \%$ in DJOS patients 6 months after the operation (both NS). LSG alone led to a relief of arterial hypertension in $50 \%$ of DIOS patients, with 3 patients remaining on antihypertensive drugs up to the second step operation. Only 1 
Table 1 Patient characteristics

\begin{tabular}{lccc}
\hline & DIOS & DJOS & Overall \\
\hline Patients & 9 & 7 (gastric plicature: $\mathrm{n}=3)$ & $1 / 6$ \\
Male/Female & $3 / 6$ & 44 & $4 / 12$ \\
Age & 52 & $117.4 \mathrm{~kg}(103-145 \mathrm{~kg})$ \\
Body weight prior to duodeno-enterostomy & $114.2 \mathrm{~kg}(85-145 \mathrm{~kg})$ & $41.60 \mathrm{~kg} / \mathrm{m}^{2}\left(35.74-47.90 \mathrm{~kg} / \mathrm{m}^{2}\right)$ \\
BMI prior to duodeno-enterostomy & $40.63 \mathrm{~kg} / \mathrm{m}^{2}\left(33.20-55.94 \mathrm{~kg} / \mathrm{m}^{2}\right)$ & \\
Body weight prior to LSG & $140.1 \mathrm{~kg}(105-175 \mathrm{~kg})$ & \\
Gap between LSG and DIOS & 17.9 months $(3.65-41.96 \mathrm{months})$ & 4 of 7 (LGB 4) \\
\%EWL before $2^{\text {nd }}$ step surgery & $31.73 \%(-2.67-69.54)$ & 9 of 16 \\
Previous bariatric surgery & 5 of 9 (gastric ballon 2, LGB 1, RYGB 2)
\end{tabular}

Values are expressed as means; laparoscopic gastric banding (LGB), Roux-en-Y gastric bypass (RYGB), \% excess weight loss (\%EWL).

patient remained on antihypertensive drugs 3 months after the DIOS operation. Interestingly, this is the same patient who also had to continue insulin treatment.

Reflux was present in the majority of patients (Table 3) with overall $87.5 \%$ of patients requiring proton-pumpinhibiting treatment. Corresponding to the shorter common channel, diarrhoea was present in $66.7 \%$ of DIOS and in $28.6 \%$ of DJOS patients. Overall, $62.5 \%$ of patients complaining of diarrhoea reported only occasional episodes. Occasional episodes of dumping were reported by only 1 patient after a DJOS operation.

\section{Discussion}

Major bariatric surgery combines a restrictive gastric component with a rearrangement of the small intestinal passage. Whenever reconnecting the stomach pouch to the intestine, the pylorus can either be preserved (BPD-DS), or excluded, as it is after common RYGB and MiniGastric-Bypass (MGB) [3,10]. In order to preserve the pylorus for a bypass-like procedure, we combined a LSG with an end-to-side duodenojeunostomy - DJOS.

Why should the pylorus be preserved? Historically, this debate was initiated after Watson introduced a pylorus- preserving alternative to the classic Whipple procedure in performing a pancreatic head resection [11]. This modification should prevent the patient from typical postgastrectomy symptoms such as dumping, diarrhoea and dyspepsia [12]. A prospective randomized trial comparing the two procedures could later demonstrate an increased quality of life regarding appetite, nausea and diarrhoea resulting in a faster regain of bodyweight [13]. For bariatric surgery, Hess et al. demonstrated a reduction of marginal ulcers by $90 \%$ and no dumping syndrome when the pylorus was preserved during a BPD/DS [14].

Postpyloric anastomosis furthermore allows for loop reconstruction, whereas a "prepyloric" gastro-entero anastomosis necessitates rerouting the biliopancreatic fluids via a foot-point or a Roux-en-Y reconstruction to avoid biliary reflux. Disregarding this principle, surgeons use a loop reconstruction without rerouting biliopancreatic fluids in performing a MGB $[10,15]$. Although this operation enables excellent weight loss with a low complication rate, operative revision after MGB was mostly due to internal bile reflux and marginal ulcers [16]. Marginal ulcers furthermore also occur after conventional RYGB in about $13 \%$ of patients, even though a

Table 2 Perioperative data

\begin{tabular}{|c|c|c|c|c|}
\hline & DIOS & DJOS & \multicolumn{2}{|c|}{ Overall } \\
\hline Surgical complication & 0 of 9 & 1 of 7 (trocar perforation) & \multicolumn{2}{|c|}{1 of $16(6.3 \%)$} \\
\hline Operative revision & 0 of 9 & 1 of 7 & \multicolumn{2}{|c|}{1 of $16(6.3 \%)$} \\
\hline Expansion on surgery & $\begin{array}{l}5 \text { of } 9 \text { (cholecystectomy 3, appendectomy 2, umbilical hernia } \\
\text { repair 1, end-to-end jejunojejunostomy after RYGB 1) }\end{array}$ & $\begin{array}{l}1 \text { of } 7 \\
\text { (gastric band removal 1) }\end{array}$ & \multirow{3}{*}{\multicolumn{2}{|c|}{$P=0.112^{4}$}} \\
\hline Duration of surgery & $120.6 \mathrm{~min}$ & $147 \min$ & & \\
\hline Length of small intestine & 808.3 cm (range: 760 - 850 cm) & $\begin{array}{l}701.4 \mathrm{~cm} \\
\text { (range: } 600-900 \mathrm{~cm} \text { ) }\end{array}$ & & \\
\hline Length of bilio-pancreatic channel & $538.3 \mathrm{~cm}$ & $235.7 \mathrm{~cm}$ & & \\
\hline Length of common channel & $245.6 \mathrm{~cm}$ & $465.7 \mathrm{~cm}$ & & \\
\hline
\end{tabular}




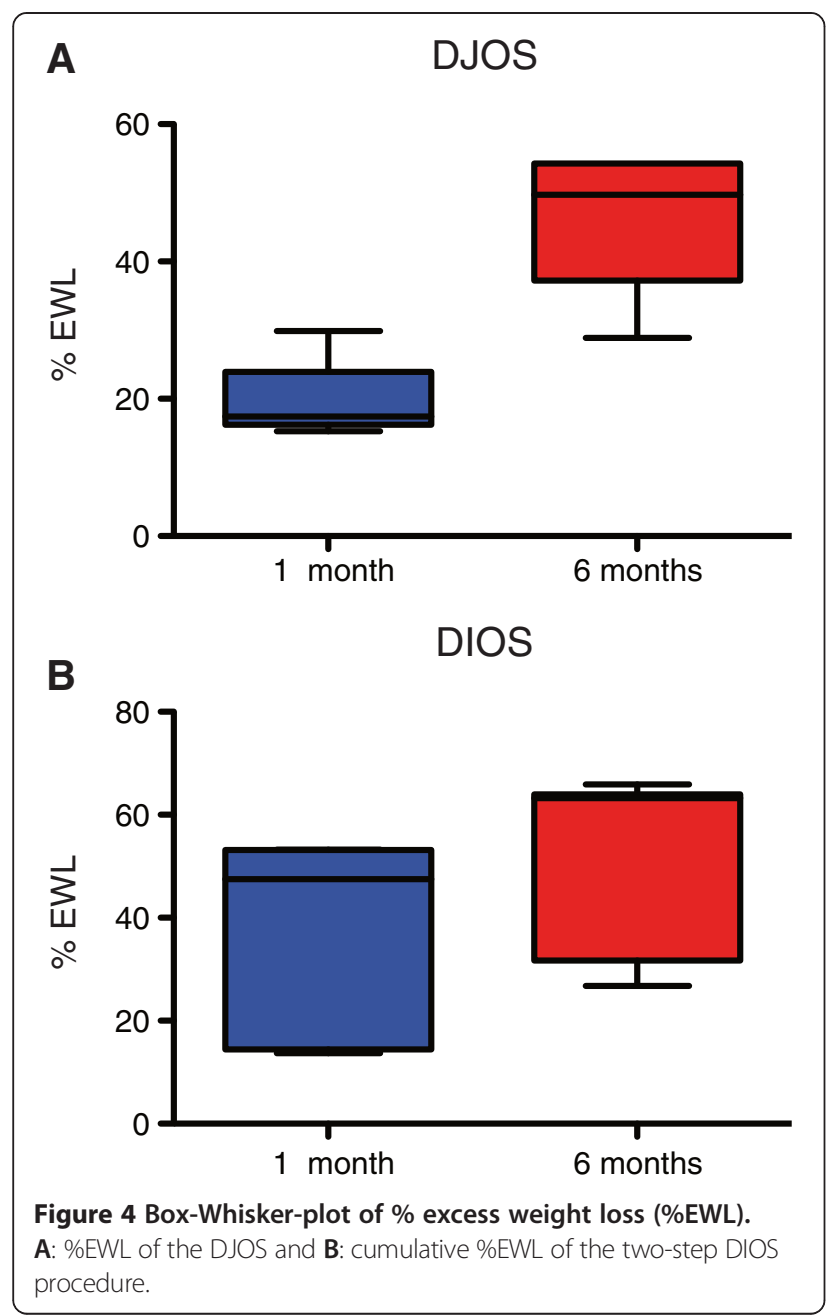

Roux-en-Y reconstruction had been performed in these patients [17].

Furthermore, pylorus preservation leaves a physiological control mechanism of food output into the small intestine preventing a dumping syndrome [18]. Dumping syndrome is an important issue after RYGB and the overall incidence may rise up to $75.9 \%$ [19]. Recently, a detailed examination of postoperative dumping syndrome showed severe problems of fatigue in $12 \%$ of patients 2 years after RYGB [20]. The current analysis of postoperative bowel habits after DJOS operations revealed that only 1 patient complained of occasional dumping-related symptoms.

Surprisingly, reflux was present in $86 \%$ of patients after the DJOS operation, despite PPI treatment and grossly asymptomatic patients preoperatively. Although we cannot test for this hypothesis, we believe that reflux is a consequence of the LSG in which it is a common phenomenon [21]. However, the reflux incidence in our own isolated LSG collective is much lower and other authors report an incidence of $25-47 \%$ [21,22]. We earlier demonstrated a thoracic sleeve migration as a cause of reflux after LSG [23]. Although performing only a limited duodenal mobilisation maintaining the right gastric artery, disruption at the duodenum and pyloric mobilisation may facilitate such a migration. Long-term follow up with close attention on reflux including structured analysis such as 24-hour $\mathrm{pH}$-manometry will further clarify the cause of increased reflux and show, whether these high numbers indeed prove to be an obstacle after DJOS operations.

In the current series, a gastric plicature was used in 3 patients after previous gastric banding. This constellation is a known risk factor for sleeve leak when performing a conventional LSG [24,25]. Gastric plicature has been introduced by Talebpour et al. as an alternative to LSG [9]. Weight loss through this technique alone may be inferior to conventional sleeve gastrectomy and randomized controlled trials have not been conducted to date [26]. However, in case of previous gastric banding and relevant perigastric scar tissue, a gastric plicature may pose an alternative to LSG as the stomach and surrounding scar tissue has not to be cut, especially when combined with additional bariatric options such as a rerouting of the intestine. Certainly to date, this option is relevant only for individual patient cases.

This early follow-up period of 6 months in a small and heterogeneous group does not allow for valid evaluation of weight loss capacity, yet weight loss noted after DJOS is within the range reported by others

Table 3 Morbidity

\begin{tabular}{lcc}
\hline & DIOS & DJOS \\
\hline Flatulence & $55.6 \%$ (all regularly) & $71.4 \%$ (1 regularly, 4 occ.) \\
Dumping & $0 \%$ & $14.3 \%$ (all occ.) \\
Diarrhoea & $66.7 \%(2$ regularly, 4 occ.) & $28.6 \%(1$ regularly, 1 occ.) \\
Reflux & $44.4 \%$ & $85.7 \%$ \\
PPI treatment & $100 \%$ & $71.4 \%$ \\
\hline
\end{tabular}

Values are expressed as fractions with subgroup differentiation in absolute number (peramphases).

'Fisher's exact test DIOS vs. DJOS. 
following RYGB $[27,28]$. Overall \%EWL of DIOS patients was considerably lower when compared to Sachez-Peraut's SADI-S collective, yet again the majority of patients had undergone pervious weight loss surgery which is known to considerably effect weight loss [7].

Weight regain is a major problem after conventional gastric bypass with up to $35 \%$ of patients experiencing an $\% E W L$ less than $60 \%$. Causes noted are dilatation of the gastric pouch or enlargement of the gastro-jejunal anastomosis [29]. Clinically, we and others observe that patients regaining weight after RYGB have often lost their feeling of satiety and subsequently consume large meals [5]. We speculate that the DJOS operation has two distinct advantages targeting these drawbacks after conventional RYGB: 1. Anastomotic dilatation will be prevented through pyloric physiological muscle calibration and, 2. LSG is known to create an excellent feeling of satiety due to a deceleration of food transit in the longitudinal part of the sleeve stomach [30].

The major predicament in analysing limb-length variations is the fact that surgeons creating a gastric bypass commonly measure the alimentary and biliopancreatic limb but neglect the common channel length. Surgeons forming a BPD, by contrast, determine the length of the common channel and alimentary limb, and in turn neglect the length of the biliopancreatic limb. Furthermore, the total small intestinal length is highly variable and ranges between 4 to nearly 10 meters [31]. We measured a comparable range of small bowel length of 6-9 $\mathrm{m}$, yet the length variation of bowel measured was large. Compared to the historical measurement of small bowel length in lean adults, the total small bowel length of obese patients was comparable to lean individuals [32].

Establishing the loop duodeno-jejunostomy the key issue was to determine an adequate anastomosis position. In conventional RYGB, weight loss is mainly due to calorie restriction, which is substantially caused by appetite control due to a modulation of entero-endocrine peptides, mainly located in the terminal ileum [33]. As this modulation is well known for current limb length variations in RYGB, the focus was to find an anastomosis position similar to conventional RYGB. Here, the alimentary limb ranges from $75 \mathrm{~cm}$ to $150 \mathrm{~cm}$ with a biliopancreatic limb length of approximately 30 $\mathrm{cm}$ [34]. Randomized controlled trials suggest that a long alimentary limb $(150 \mathrm{~cm})$ might be preferable for the super-obese [35,36]. However, Stefinidis et al. reviewing the "Importance of the Length of the Limbs for Gastric Bypass Patients" find no clear recommendation [34]. In MGB, the gastro-jejunostomy in usually formed at $150 \mathrm{~cm}$ [10]. Some authors suggest an increase in length by $10 \mathrm{~cm}$ for every BMI point above $40 \mathrm{~kg} / \mathrm{m}^{2}$ (MGB for all) [15].
To account for inter-individual differences, as outlined above, we decided to place the duodeno-jejunostomy after $1 / 3$ of small bowel length, bypassing an average of $236 \mathrm{~cm}$ in performing a DJOS operation. Taking into account that the loop reconstruction combines the alimentary and biliopancreatic limb, DJOS resembles a long limb RYGB $(150 \mathrm{~cm}$ plus $30 \mathrm{~cm})$.

For the malabsorptive DIOS operation, the adequate anastomosis position had to be carefully selected in order to prevent excessive malabsorption. As there is no alimentary limb when conducting a loop reconstruction, the common channel had to be considerably longer than in classic BPD surgery. Sanchez-Pernaute et al. extensively reviewed limb length variations when initially describing the SADI-S operation, ultimately deciding to form a common channel of $200 \mathrm{~cm}$ [37]. As the SADI-S operation has proven to be safe and effective with no relevant malabsorption in mid-term follow up, anastomosis position for the DIOS operation should be similar [7]. Yet, provided that the overall proportional energy resorption of food consumed does not grossly depend on bowel length, it seems consistent that leaving a $200 \mathrm{~cm}$ common channel at a total bowel length of $500 \mathrm{~cm}$ causes greater possible malabsorption than the same common channel at $900 \mathrm{~cm}$ overall bowel length.

Based on the considerations above, we decided to place the duodeno-ileostomy after $2 / 3$ of the small intestine, leaving a common channel of $1 / 3$. For maximum safety, the common channel was never under $200 \mathrm{~cm}$ in length. The $2 / 3$ position left a mean common channel length of $245 \mathrm{~cm}$, thus approximately $20 \%$ more compared to the SADI-S operation [7].

\section{Conclusions}

Although two different metabolic principles underlie the DJOS and DIOS operation, performing loop duodenoenterostomies with sleeve gastrectomy essentially breaks down bariatric surgery into exactly these two distinct elements, leaving the possibility for individual adaptation. The early results of this small and heterogeneous series most importantly show no mortality and no complication related to the duodeno-enterostomy. Pylorus-preserving duodeno-enterostomies with sleeve gastrectomy may open new technical alternatives in bariatric surgery. If the DJOS and DIOS operations prove to be beneficial will have to be evaluated in randomized controlled trials.

\section{Abbreviations}

BMI: Body mass index; BPD: Biliopancreatic diversion; BPD/DS: Biliopancreatic diversion with duodenal switch; CT: Computed tomograpy; DIOS: Duodenoileostomy with sleeve gastrectomy; DJOS: Duodeno-jejunostomy with sleeve gastrectomy; LSG: Laparsocopic sleeve gastrectomy; MGB: Mini gastric bypass; RYGB: Roux-en-Y gastric bypass; SADI-S: Single anastomosis duodeno-ileostomy associated to a sleeve gastectomy; \%EWL: Excess weight loss. 


\section{Competing interests}

Jodok Matthias Grueneberger, Iwona Karcz-Socha, Goran Marjanovic, Simon Kuesters, Krystyna Zwirska-Korczala, Katharina Schmidt and W. Konrad Karcz have no conflicts of interest.

\section{Authors' contributions}

MG, GM, SK and KK participaed as surgeons for DIOS and DJOS operations, MG, KS and KK have drafted the manuscript, IK-S and KZ-K critically revised the manuscript. All authors read and approved the final manuscript.

\section{Author details}

${ }^{1}$ Department of General and Visceral Surgery, University of Freiburg, Hugstetter Strasse 55, 79106 Freiburg, Germany. '2Department of Physiology, Silesian Medical University, Katowitz, Poland. ${ }^{3}$ Department of General Surgery, University of Schleswig-Holstein, Campus Lübeck, Lübeck, Germany.

Received: 11 September 2013 Accepted: 27 March 2014

Published: 11 April 2014

\section{References}

1. Mingrone G, Panunzi S, De Gaetano A, Guidone C, laconelli A, Leccesi L, Nanni G, Pomp A, Castagneto M, Ghirlanda G, Rubino F: Bariatric surgery versus conventional medical therapy for type 2 diabetes. $N$ Engl J Med 2012, 366:1577-1585.

2. Sjostrom L, Lindroos AK, Peltonen M, Torgerson J, Bouchard C, Carlsson B, Dahlgren S, Larsson B, Narbro K, Sjostrom CD, Sullivan M, Wedel H, Swedish Obese Subjects Study Scientific Group: Lifestyle, diabetes, and cardiovascular risk factors 10 years after bariatric surgery. $N$ Engl J Med 2004, 351:2683-2693.

3. Marceau P, Biron S, Bourque RA, Potvin M, Hould FS, Simard S: Biliopancreatic Diversion with a New Type of Gastrectomy. Obes Surg 1993, 3:29-35.

4. Padwal R, Klarenbach S, Wiebe N, Birch D, Karmali S, Manns B, Hazel M, Sharma AM, Tonelli M: Bariatric surgery: a systematic review and network meta-analysis of randomized trials. Obes Rev 2011, 12:602-621.

5. Christou NV, Look D, Maclean LD: Weight gain after short- and long-limb gastric bypass in patients followed for longer than 10 years. Ann Surg 2006, 244:734-740.

6. Swartz DE, Mobley E, Felix EL: Bile reflux after Roux-en-Y gastric bypass: an unrecognized cause of postoperative pain. Surg Obes Relat Dis 2009, 5:27-30

7. Sanchez-Pernaute A, Herrera MA, Perez-Aguirre ME, Talavera P, Cabrerizo L, Matia P, Diez-Valladares L, Barabash A, Martin-Antona E, Garcia-Botella A, Garcia-Almenta EM, Torres A: Single anastomosis duodeno-ileal bypass with sleeve gastrectomy (SADI-S). One to three-year follow-up. Obes Surg 2010, 20:1720-1726.

8. Karcz WK, Marjanovic G, Grueneberger J, Baumann T, Bukhari W, Krawczykowski D, Kuesters S: Banded sleeve gastrectomy using the GaBP ring-surgical technique. Obes Facts 2011, 4:77-80

9. Talebpour A, Motamedi SM, Vahidi H: Twelve year experience of laparoscopic gastric plication in morbid obesity: development of the technique and patient outcomes. Ann Surg Innov Res 2012, 6:7.

10. Rutledge R, Walsh TR: Continued excellent results with the minigastric bypass: six-year study in 2,410 patients. Obes Surg 2005, 15:1304-1308

11. Watson $\mathrm{K}$ : Carcinoma of ampulla of vater successful radical resection. Brit J Surg 1944, 31:368-373.

12. Traverso LW, Longmire WP Jr: Preservation of the pylorus in pancreaticoduodenectomy. Surg Gynecol Obstet 1978, 146:959-962.

13. Wenger FA, Jacobi CA, Haubold K, Zieren HU, Muller JM: [Gastrointestinal quality of life after duodenopancreatectomy in pancreatic carcinoma. Preliminary results of a prospective randomized study: pancreatoduodenectomy or pylorus-preserving pancreatoduodenectomy]. Chirurg 1999, 70:1454-1459.

14. Hess DS, Hess DW: Biliopancreatic diversion with a duodenal switch. Obes Surg 1998, 8:267-282.

15. Noun R, Skaff J, Riachi E, Daher R, Antoun NA, Nasr M: One thousand consecutive mini-gastric bypass: short- and long-term outcome. Obes Surg 2012, 22:697-703.
16. Johnson WH, Fernanadez AZ, Farrell TM, Macdonald KG, Grant JP, McMahon RL, Pryor AD, Wolfe LG, DeMaria EJ: Surgical revision of loop ("mini") gastric bypass procedure: multicenter review of complications and conversions to Roux-en-Y gastric bypass. Surg Obes Relat Dis 2007, 3:37-41.

17. Obeid A, Long J, Kakade M, Clements RH, Stahl R, Grams J: Laparoscopic Roux-en-Y gastric bypass: long term clinical outcomes. Surg Endosc 2012 26:3515-3520

18. Shah M, Simha V, Garg A: Review: long-term impact of bariatric surgery on body weight, comorbidities, and nutritional status. J Clin Endocrinol Metab 2006, 91:4223-4231.

19. Mallory GN, Macgregor AM, Rand CS: The Influence of Dumping on Weight Loss After Gastric Restrictive Surgery for Morbid Obesity. Obes Surg 1996, 6:474-478.

20. Laurenius A, Olbers T, Naslund I, Karlsson J: Dumping syndrome following gastric bypass: validation of the dumping symptom rating scale. Obes Surg 2013, 23:740-755.

21. Carter PR, LeBlanc KA, Hausmann MG, Kleinpeter KP, deBarros SN, Jones SM: Association between gastroesophageal reflux disease and laparoscopic sleeve gastrectomy. Surg Obes Relat Dis 2011, 7:569-572.

22. Himpens J, Dobbeleir J, Peeters G: Long-term results of laparoscopic sleeve gastrectomy for obesity. Ann Surg 2010, 252:319-324.

23. Baumann T, Grueneberger J, Pache G, Kuesters S, Marjanovic G, Kulemann B, Holzner P, Karcz-Socha I, Suesslin D, Hopt UT, Langer M, Karcz WK: Three-dimensional stomach analysis with computed tomography after laparoscopic sleeve gastrectomy: sleeve dilation and thoracic migration. Surg Endosc 2011, 25:2323-2329.

24. Alevizos L, Linardoutsos D, Menenakos E, Stamou K, Vlachos K, Zografos G, Leandros E: Routine abdominal drains after laparoscopic sleeve gastrectomy: a retrospective review of 353 patients. Obes Surg 2011, 21:687-691

25. Goitein D, Feigin A, Segal-Lieberman G, Goitein O, Papa MZ, Zippel D: Laparoscopic sleeve gastrectomy as a revisional option after gastric band failure. Surg Endosc 2011, 25:2626-2630.

26. Shen D, Ye H, Wang Y, Ji Y, Zhan X, Zhu J, Li W: Comparison of short-term outcomes between laparoscopic greater curvature plication and laparoscopic sleeve gastrectomy. Surg Endosc 2013, 27:2768-2774.

27. Brethauer SA, Heneghan HM, Eldar S, Gatmaitan P, Huang H, Kashyap S, Gornik HL, Kirwan JP, Schauer PR: Early effects of gastric bypass on endothelial function, inflammation, and cardiovascular risk in obese patients. Surg Endosc 2011, 25:2650-2659.

28. Lakdawala MA, Bhasker A, Mulchandani D, Goel S, Jain S: Comparison between the results of laparoscopic sleeve gastrectomy and laparoscopic Roux-en-Y gastric bypass in the Indian population: a retrospective 1 year study. Obes Surg 2010, 20:1-6.

29. Kuesters S, Grueneberger JM, Baumann T, Bukhari W, Daoud M, Hopt UT, Karcz WK: Revisionary bariatric surgery: indications and outcome of 100 consecutive operations at a single center. Surg Endosc 2012, 26:1718-1723.

30. Baumann T, Kuesters S, Grueneberger J, Marjanovic G, Zimmermann L, Schaefer AO, Hopt UT, Langer M, Karcz WK: Time-resolved MRI after ingestion of liquids reveals motility changes after laparoscopic sleeve gastrectomy-preliminary results. Obes Surg 2011, 21:95-101.

31. Savassi-Rocha AL, Diniz MT, Savassi-Rocha PR, Ferreira JT, Rodrigues de Almeida Sanches S, Diniz Mde F, Gomes de Barros H, Fonseca IK: Influence of jejunoileal and common limb length on weight loss following Roux-en-Y gastric bypass. Obes Surg 2008, 18:1364-1368

32. Underhill BM: Intestinal length in man. Br Med J 1955, 2:1243-1246.

33. le Roux CW, Welbourn R, Werling M, Osborne A, Kokkinos A, Laurenius A, Lonroth H, Fandriks L, Ghatei MA, Bloom SR, Olbers T: Gut hormones as mediators of appetite and weight loss after Roux-en-Y gastric bypass. Ann Surg 2007, 246:780-785.

34. Stefanidis D, Kuwada TS, Gersin KS: The importance of the length of the limbs for gastric bypass patients-an evidence-based review. Obes Surg 2011, 21:119-124.

35. Brolin RE, Kenler HA, Gorman JH, Cody RP: Long-limb gastric bypass in the superobese. A prospective randomized study. Ann Surg 1992, 215:387-395.

36. Pinheiro JS, Schiavon CA, Pereira PB, Correa JL, Noujaim P, Cohen R: Long-long limb Roux-en-Y gastric bypass is more efficacious in 
treatment of type 2 diabetes and lipid disorders in super-obese patients. Surg Obes Relat Dis 2008, 4:521-525. discussion 526-527.

37. Sanchez-Pernaute A, Rubio Herrera MA, Perez-Aguirre E, Garcia Perez JC, Cabrerizo L, Diez Valladares L, Fernandez C, Talavera P, Torres A: Proximal duodenal-ileal end-to-side bypass with sleeve gastrectomy: proposed technique. Obes Surg 2007, 17:1614-1618.

doi:10.1186/1471-2482-14-20

Cite this article as: Grueneberger et al:: Pylorus preserving loop duodeno-enterostomy with sleeve gastrectomy - preliminary results. BMC Surgery 2014 14:20.

\section{Submit your next manuscript to BioMed Central and take full advantage of:}

- Convenient online submission

- Thorough peer review

- No space constraints or color figure charges

- Immediate publication on acceptance

- Inclusion in PubMed, CAS, Scopus and Google Scholar

- Research which is freely available for redistribution 